\title{
The Impact of a Collaborative Knowledge Base on a Fostering Communities of Learners model in Post-Secondary Large Lectures
}

\author{
Steven P. Ehrlick ${ }^{1}$, Jim D. Slotta ${ }^{2}$ \\ ${ }^{1}$ Ryerson University, Canada \\ ${ }^{2}$ Boston College, USA
}

\begin{abstract}
This design-based research study of a second year undergraduate course involved the enactment of the Fostering Communities of Learners (FCL) pedagogical model augmented with elements of the Knowledge Community and Inquiry (KCI) model by the addition of a digital collaborative knowledge base $(C K B)$. The study involved the re-design of a course comprised of lectures and break-out tutorials which covered basic business concepts for undergraduate media students. The investigation examined the ways in which a learning community pedagogical approach could be enacted in an undergraduate large lecture course through a scaffolded, complex curricular design that utilizes active and inquiry-based learning. By appropriating design elements from KCI, a CKB was introduced as a major research element in the curricular design. The CKB was intended to be a

persistent online hub of ideas, serving as a resource for completion of a major group project. Results indicate that students participated in more individual inquiry, collaborated with peers and perceived themselves to be part of a class-wide learning community. The study concluded that a learning community ethos can be established in an undergraduate large lecture through the recursive cycle of individual inquiry, research discussion in lectures and by reference to $C K B$ research exercises in group tutorial sessions by way of reciprocal teaching, cross-talk and jigsaw activities.
\end{abstract}

\section{Introduction}

Developed in the 1990s by Brown and Campione [1], the Fostering Communities of learners (FCL) pedagogical approach draws upon social constructivist principles of learning [2] and the belief that "learning is intrinsically entangled with situations" [3]. FCL and other such "learning community" approaches, such as Knowledge Community and Inquiry (KCI) [4], on their face appear to be pedagogical models well suited to address the needs of modern students and the acquisition of 21 st century skills. However, much of the initial applied research in learning communities has waned, due to the intrinsic challenges of implementing this approach - particularly in secondary or higher education where course expectations tend to be at odds with deep student inquiry [5]. Some learning community frameworks such KCI continue to be studied, but others specifically FCL - have not seen much research, beyond initial studies, with little current examination of the execution, modification and evaluation of its fundamental principles. This paper presents a study that implemented FCL in a new context, a large lecture university course, by first enacting the model then augmenting it to determine its relevance as a viable alternative to large lecture course delivery. Large lectures at the university level present serious challenges no matter the delivery style or mode of instruction. Many scholars have promoted the conversion of classrooms into learning communities with inquiry learning as its focus [6]. Individual and group inquiry into challenging content promises to install in students the capacity to develop their own conjectures or models [7]. Completing major projects [1] also reinforce this knowledge, memorialized in and supported by a user-generated knowledge database [8]. However, to use a model as complex and comprehensive as a learning community approach, in which the whole class must be engaged collectively in elaborate learning designs, presents serious challenges to instructors. FCL offers a well specified model for this approach, which allowed for the redesign of a course whilst preserving its learning goals. It was therefore the goal of this study to implement an FCL curricular design, modified from its original application in K-12 middle school settings, for enactment in a university setting. The FCL model was implemented through a scaffolded curricular design that utilized active and inquirybased learning. In a K-12 context, adoption of a learning community approach requires significant changes to the curriculum, approval from school boards, and challenging negotiations with students who are unaccustomed to such forms of learning [9]. In the university setting, where the instructor is also the researcher, and students are motivated and mature, many of these hurdles could be expected to be reduced. Other challenges presented themselves the size of university classrooms, the lecture-hall configuration of the room, and the norms and expectations of particular forms of instruction (i.e., 
lectures, homework sets,etc.). One of the goals of this study was to explore the shifting challenges that accompany the move of a pedagogical model designed for K-12 to the university level.

\section{Learning Communities, Knowledge Building Communities, and a Blended View}

FCL was developed as a pedagogical model to help students in a classroom work as a learning community. The overall structure consists of (1) individual and group research on core topics, (2) sharing research through crosstalk, jigsaw and reciprocal teaching, and (3) the creation and presentation of a consequential task [1]. Research is conducted in groups on sub-topics that require deep understanding. The recursive design of research, sharing and performing works best with "big ideas", transforming the classroom into a learning community. As they grapple with a rich-content topics, students of varying abilities and understanding (the more adept described by Brown as "majoring") [1], work towards consensus. Students who are challenged by the content learn from those in the group who grasp the concepts [2]. FCL then, at its simplest, is a threestep process research, sharing and a consequential task [1] (Figure $1)$.

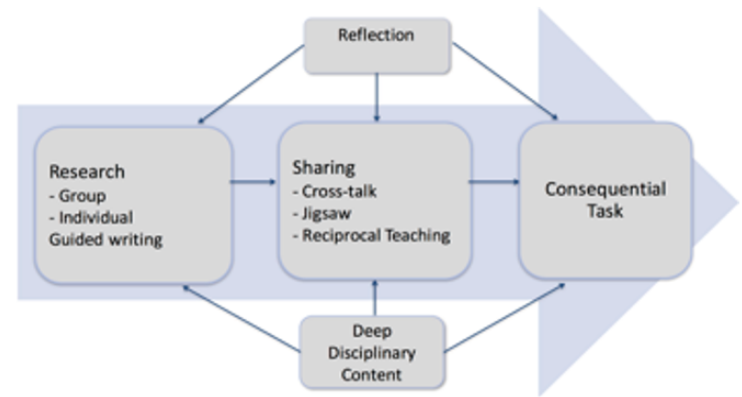

Figure 1. Visual representation of FCL as conceived by Brown and Campione [1]

Students in their groups are responsible for individual and collective inquiry. The research approach is left to the teacher to explain, as the literature does not prescribe the way in which group research is conducted. For FCL to operate as its authors intend, it is important that the topic have sufficient rigour and depth to sustain deep individual and group research [1]. The topic should be challenging enough for students to be able to stretch their abilities and knowledge base within their particular ZPD. The authors also stress "guided writing" where students codify their research prior to sharing their results, compelling students to operate at the outer limits of their ZPD and thereby display optimum output. However, there is no guideline or evidence to support how or if this learning process occurs nor does the literature provide the tools by which a teacher can facilitate this occurrence. FCL also encourages consultation with experts, usually by way of guest lectures. Once expertise is gained through inquiry activities, the sharing process begins. Using cross-talk, jigsaw and other sharing techniques, the class in their groups and as a whole begin to conceptualize and synthesize the deep content. The final part of this research cycle is a "consequential task", which may take the form of a culminating project, performance or even a comprehensive test. Guided assessment methods are used where students confront problems slightly beyond their grasp and are then provided support to solve these problems [1]. In related work Scardamalia and Bereiter advanced the model of Knowledge Building (KB) [10], which introduced the construct of an external "knowledge base" which served as a persistent record and repository of student research and collaboration, supplying resources for sharing, discussion and argumentation, plus capturing the products of student effort. The KB model entails a process of "idea improvement" in which students build on one another's ideas, develop higher level syntheses, and advance the community's knowledge [10]. KB can be even more challenging to implement than a learning community approach, taking up to two years to establish an appropriate pedagogical climate for KB to succeed [7].

In response to the challenges inherent in the learning community approach, Slotta and his colleagues [4, 5] have advanced $\mathrm{KCI}$ as a pedagogical design that scaffolds students and teachers in carefully designed inquiry scripts. Central to $\mathrm{KCI}$ is the creation of a collective knowledge base of a particular theme, which becomes a resource repository for the students. The knowledge base is populated during individual and small group inquiry, argumentation and discussion, and continues to serve as a resource as students refine their understanding through scaffolded activities.

KCI is based upon three guiding principles: (1) that students work collectively and collaboratively to build their knowledge base, which is both a product of, and resource for inquiry activities; (2) that inquiry activities are connected to themes emerging from the community's collective interests, and (3) that inquiry activities provide assessable outcomes that are linked to the required learning goals. It should also be noted that the teacher's role in KCI is included in the curricular script, in addition to being responsible for the overall coordination of the curriculum [4].

Another contribution of $\mathrm{KCI}$ is its inclusion of a preliminary epistemological orientation for students and teachers (often delivered as an "icebreaker") that orients all participants to the KCI approach. This creates for the students a metacognitive awareness of, and strategies for the mechanics of learning, the 
execution of the curricular design and an initial understanding of the dynamics at play in the building of a learning community [8]

With the addition of a collective knowledge base to the FCL framework, the design approaches that of KCI (differing in the retention of the core FCL structures). Slotta (personal communication) credits FCL as the theoretical inspiration of KCI. FCL and KCI share the goal of making the learning community approach more accessible, permanent and practicable for instructors. This study addresses the challenge of having a large population contributing their research to a permanent repository, in both technical and pedagogical terms.

\section{Method}

Design-based research allows education researchers to validate their studies by situating them in an actual classroom and "ensures that the results can be effectively used to assess, inform, and improve practice in at least this one (and likely other) contexts" [11] (Figure 2).

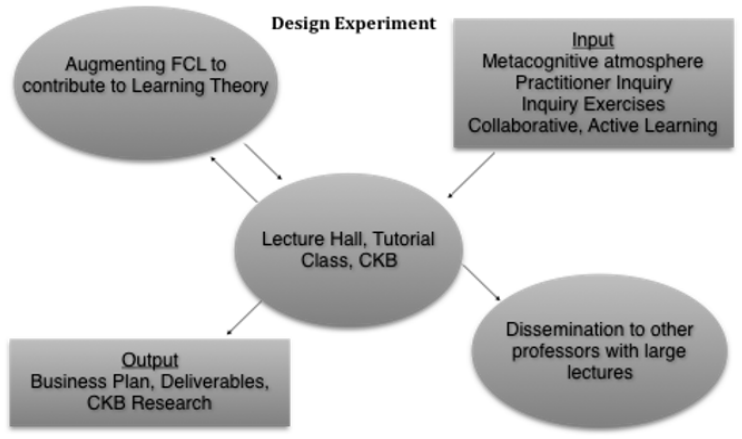

Figure 2. Modified graphic showing FCL features of design experiments supplemented with particulars from this study

The study consisted of two iterations of an undergraduate course. The course examined was an introductory general business course designed to introduce undergraduate media students to basic business, legal and financial aspects of the media industry. This course is a required/elective hybrid, drawing students from three undergraduate media programs. The 1st iteration included 236 students; the 2 nd iteration was populated by 231 students. The professor conducted a three-hour lecture during oddnumbered weeks. Even-numbered weeks consisted of a one-hour lecture plus a two-hour tutorial (approximately 20 students per section). One of the authors was the professor for the course and led one tutorial with four teaching assistants (TAs) leading the remaining eleven.

The six tutorials (one every two weeks) were designed to incrementally and broadly increase individual and collective competencies towards the creation of a business plan for the company. Material and pedagogical scaffolds (e.g., Google Doc pages that included clear headers for supporting targeted content structures) were developed to help "scaffold" students in their progress. The tutorials were scripted in order to enable teaching assistants to lead them with minimal variance, in terms of the curricular design. Student experience was captured by way of the following qualitative methods, including 1) preand post- surveys that assess the level of their business knowledge; 2) student and TA focus groups; 3) video recording of group work; and 4) content analysis of the students' generated artifacts (tutorial-directed writing and a reflective test).

\subsection{First Design Iteration}

The 1st iteration was run during the Fall term of 2015 with 236 students enrolled. For 179 Media Production students, the course was required. Fiftyfour students from the first year Sport Media cohort elected this course over a business course provided by the university's business school. Two students came from the Creative Industries school and one from a program outside of the faculty that houses the creative schools. Four TAs were hired to lead the tutorials and grade assignments, one $\mathrm{PhD}$ candidate, two Master of Arts students and one fourth year undergraduate Media Production student. The course is further described in Section 3.2.

The course under study was conceived strategically as a foundational business course for second year media production students. Prior to its creation, professors teaching professionally-related business and legal courses found that topics such as the law of contract, copyright law, corporate structure and the art of negotiation were being taught in multiple courses as a baseline for other contextual topics. A decision was made to consolidate these foundational concepts in one required course. This course would eliminate duplication of subject matter and provide content while more advanced business and legal courses would provide context. Prior to the running of the first iteration in the Fall 2015, this course was taught two times without tutorials or the implementation of FCL principles. But the core learning outcomes have remained the same.

The purpose of the 1st iteration was to design a curriculum that adhered to FCL principles, and then to examine whether that design could be effectively and accurately implemented. Once satisfied that the design faithfully applied FCL principles, the course proceeded with an enactment of the curriculum. The enactment during the 1 st iteration revealed that the curriculum did adhere to FCL, insofar as the tutorials were concerned, and that students in their tutorials performed appropriately. Although a successful design and enactment occurred, there was no sense that students learned collaboratively other than in their tutorial groups. In other words, the only 
manifestation of "learning community" occurred in the tutorials. Field notes were the primary data used in this regard. Two focus groups, one with students and one with the TAs, were transcribed for analysis. To examine the effectiveness of the design in achieving stated learning outcomes, grades from a test, bi-weekly directed writing summaries created by groups during tutorials and the final assignment (a business plan), were analyzed. Results were achieved through an analysis of field notes, focus group transcripts, pre- and -post surveys and grades. Field notes and focus group transcripts were relied upon to gain perspective, of myself, the TAs, and the students, as to the effectiveness of FCL activities and for impressions of the effectiveness of various FCLprescribed activities. By employing a variety of methods (focus group, surveys, grades, student artifacts, test) an analysis of adherence and enactment to the curricular design was undertaken.

\subsection{Second Design Iteration}

The focus of the 2nd iteration, in addition to adherence and implementation of the curricular design, was to augment FCL with a Collaborative Knowledge Base (CKB), meant to serve as a permanent repository for individual inquiry and to determine if the addition of this student-generated knowledge base would be an effective means toward establishing a sense of classwide community. The most significant digital technology utilized was a Google Doc spreadsheet which served as the home for individual inquiry and a collaborative platform for all students in the course.

The CKB was intended to be a permanent online hub of ideas, the content of which would be impossible for a single student to amass if working independently. It was a form of research library that all students and student groups could contribute to and benefit from, as well as serving as a resource for completion of their consequential task, a business plan. Lectures (in both iterations) were designed to introduce new topic areas (e.g. financial instruments) and serve as benchmark lessons where "big ideas and deep principles" are introduced, sometimes by an expert guest [1]. Four groups were formed in each tutorial and these groups became virtual corporations with shareholders, directors and officers (all roles filled by group members). Five officers were appointed at a Director's meeting: CEO, CFO, COO, V.P. Legal and V.P. Marketing and Sales. There were five Google Docs, one for each officer from the 48 corporations created in the 12 tutorials (four companies per tutorial). Throughout the term, students were given five research tasks specific to the office they held. Their research was uploaded to a Google Doc (Figure 3). Each office (CEO, CFO, etc.) had a dedicated Google Doc page so that students holding that same office (i.e., across Companies) could see one another's work.

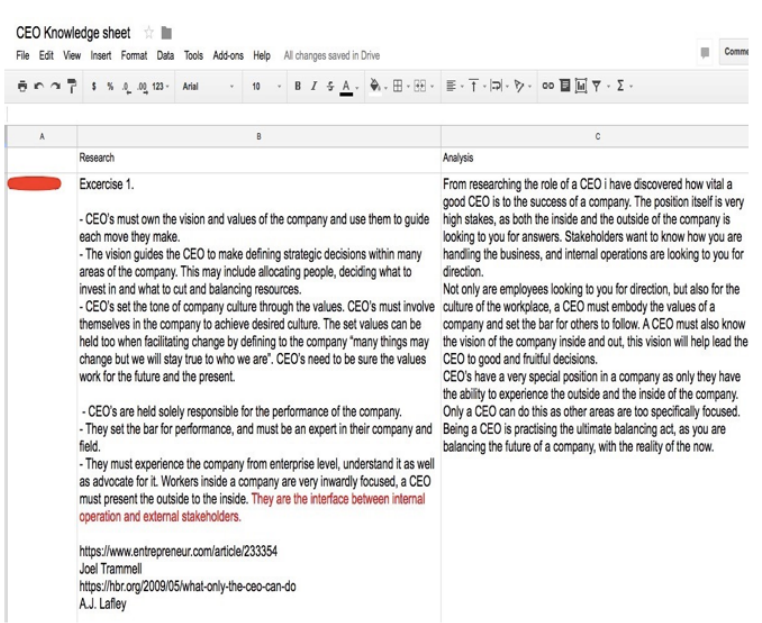

Figure 3. Sample Collaborative Knowledge base entry for Exercise 1. Students research a topic and provide analysis

In week ten of the 12-week course students wrote an open-book reflective test. Question 2 of the test asked students to describe how the CKB exercises aided them in understanding their corporate role and the section of the business that was their responsibility. It further asked how, if at all, reading the work of other officers from different companies help their understanding of the topics being researched. The test was written on computers and uploaded to a course management system, facilitating content analysis of answers.

\section{Results}

The 1st iteration demonstrated that an FCLdesigned curriculum could be successfully enacted in a university level large lecture, however, the community of learners at the core of FCL was only achieved in tutorials. Students in the 1 st iteration focus group mentioned working collaboratively with their group members but their sense of community did not extend beyond their group and tutorial section. The first iteration design created de facto, 12 distinct communities of learners.

These communities did not extend beyond the confines of the tutorial. The professor struggled to infuse the lecture hall with a learning community atmosphere. Attempts were made to engage students regarding their corporate offices when the lecture topic covered their area of responsibility, but these attempts were ad hoc at best, generating discussion but having little discernable impact on fostering a learning community during lectures. Thus, after the completion of the 1 st iteration, there remained the unresolved goal of creating a sense of overall community within the larger lecture population. 
Several graded assessments from the 1st iteration provided a measurement of student learning. The business plan, in its role as the culminating assignment, incorporated many learning outcomes, including corporate structure, copyright law, contract law, finance and management. Overall, grades for the business plan were high, with $51.2 \%$ of student groups achieving a letter grade in the As, 7.2.\% of whom received an $\mathrm{A}+$. This is very similar to the grades from the previous year's course when the class was run with the same content but with truncated versions of the tutorials in this study, conducted then within the confines of the movie theatre in the last half hour of lecture time. Similar results also occurred in the test, with median grades of $80 \%$ and $81.7 \%$ for the prior year's class and 1 st iteration, respectively. The final grade median was $81.85 \%$ for the previous year and a slightly higher $83.9 \%$ for the 1 st iteration. Thus, grades in the course remained high, if not slightly higher.

More difficult to assess was the extent to which the course prepared students for future businessrelated courses and their careers. Four students in the focus group expressed surprise at the procedures, activities and knowledge required to start a business. One student expressed her experience this way:

For me it was finance. It's shocking. You're on your own when starting a business and you have to build up everything. I own a house my parents gave me and I've gotten things from other people, but starting a business you have to start from scratch in terms of buying everything, and it's a lot of stuff.

Other students had their eyes opened in a positive way, such as this student:

I found it interesting how our group came up with our business idea. We started out wanting to make a small film but none of us were interested in that in the end. So we flipped it around and did a recording studio and it was cool to look at the equipment we wanted to buy and design the office and everything.

All focus group members had favourable opinions on the lecture/tutorial format, feeling that the tutorials gave them the time to work with their groups and conduct research individually and collectively during a prescribed time, which aided their creation of a business plan. There were the usual issues raised about group members who did not pull their weight during tutorial workshops and the writing of the business plan.

Perhaps the only statement that can be made conclusively about the achievement of learning outcomes during the 1st iteration was that the curricular design did no harm. From a practitioner perspective, learning outcomes were achieved through the enactment of the curriculum at least as effectively as in previous years. As the practitioner and researcher, one of the authors was able to observe groups in his tutorial section first-hand. This researcher was mindful of the Hawthorne effect and was initially concerned that his presence would have a beneficial effect on grades and in-class research but was satisfied after in retrospect that this did not occur. There was reason to consider that a kind of reverse Hawthorne effect was occurring, with the researcher's tutorial group of students feeling more comfortable and less pressured by having the professor as their tutorial leader and not a graduate or undergraduate student with whom they were unfamiliar and who were not much older than they were. As one of the researcher's students put it:

You were both the professor and my tutorial instructor, so for me you were the teacher figure but also the moderator and guiding hand [in the tutorials]. Even when we did ask questions, you wouldn't directly answer them. You would lead us to an answer so it was more like, "I taught you what you need to know; you should know this; these are the tools you have. Go figure it out." And it worked. You were part teacher and part someone pushing us off the bridge...in a nice way!

There was a direct link between learning activities and the consequential task. By scripting tasks and scaffolding the tutorials progressively throughout the term, students gained expertise that pertained to their roles as officers in their companies and proficiency in the skills required to create a business plan. Different tasks resulted in different types of learning. During jigsaw activities, emissaries who travelled from group to group were observed to gain confidence with each visit, honing their delivery skills with repetition. In reciprocal teaching discussions, officers majored in their corporate responsibilities, taking charge of subject matter within their area of expertise

The CKB from the 2nd iteration was analyzed for evidence of its effectiveness as a medium for individual inquiry and whether students used and valued the research of others.

Question 2 of test was analyzed to determine how students used the CKB as a resource both individually, and collectively, in their groups. The CKB was also analyzed to the extent in which students voluntarily went deeply into their research topics. Grades were compared between the 1 st and 2nd iterations to determine the effect, if any, of the CKB on learning.

The test conducted during the $1 \mathrm{st}$ iteration produced a median score of $81.7 \%$. The 2 nd iteration median test score was $82.4 \%$. The 2 nd iteration test saw a $9.4 \%$ increase in the number of scores over $90 \%$ (see Figure 4). Notable as well, is that fact while the frequency of students with the highest marks was significantly higher in the 2nd iteration, overall, students in the 1 st iteration fared better in the test. Final grades for the course showed very comparable results. The median final grade for the two classes was $83 \%$ and $83.9 \%$ for 1 st and 2 nd iterations, respectively. One particular score that 
stood out was the number of grades of A (85 to $89.5 \%$ ) in both iterations of the course, with a $10.4 \%$ increase of students achieving an $\mathrm{A}$ in the 2nd iteration when compared to the 1 st iteration grades. None of these metrics offer definitve evidence that the inclusion of a CKB into the curriculum significantly altered grades from one iteration to the other, except for an increase in the number of $\mathrm{A}+$ students in the 2nd iteration.

The notion of a consequential task as prescribed by Brown and Campione [1] was to motivate students to apply their shared research to solve a problem by accessing their deep knowledge of the subject area [12]. Throughout the tutorial experience during the 2nd iteration, students were required to visit the CKB collectively to discuss the research of each member of their "Company". Reciprocal teaching by way of student-led discussion provided each officer of the Company with a platform to inform fellow officers as to their research findings so that all officers provided separate pieces of the overall topic area. Grades for the business plan show the most significant disparity between the two iterations. The student frequency for the grade range of A- to A+ (between $80 \%$ and $100 \%$ ) was $51.2 \%$ for the 1 st and $61.5 \%$ for the 2 nd iteration.

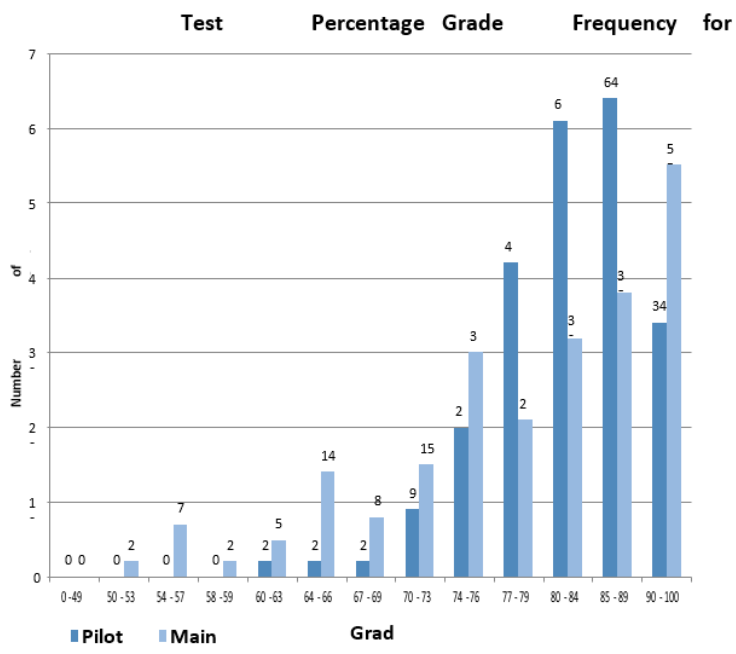

Figure 4. Grade frequency for test. 236 and 229 students took the test during the 1st and 2 nd iterations, respectively

Grades were helpful in determining the effect of the $\mathrm{CKB}$ on learning, however, the median for all assessments show that most students achieved very high grades on average. Of greater interest was a qualitative examination of the ethos created by the $\mathrm{CKB}$. Did the CKB foster inquiry beyond what was required in the five exercises? Did the ability to read the work of others, not only group members but any student in the class generate a sense of learning community? Was the creation of the business plan an instance of collaborative learning? The content of the 2nd iteration focus group and the answers for question 2 of the test revealed several notable themes. For instance, $50 \%$ percent of the student population made favourable comments concerning the benefit they gained from reading the work of other officers from other companies in the CKB. As one student noted:

I found reading other student's [research] helped mine aside from my own research because they would find different articles and perspectives I didn't know I had to do that too as VP Legal. So It was definitely helpful giving me a more well-rounded understanding of my role as opposed to a biased one from media.

Students in the 2 nd iteration focus group (eight students) were asked if they felt like they were part of a class-wide community of learners. The answer was a unanimous yes. This was facilitated by putting the CKB Google Doc onscreen during lectures and asking selected students whose work was onscreen to talk about their research. One student responded:

I would reach out to [other COO officers] and ask for help from some whom I didn't know personally and that was kind of cool. But even in the lectures, the personal anecdotes and stories, and people who were comfortable speaking and having discussions, was helpful because they were in-depth and interesting; it was very different from any other lecture where you just get in and sit down. You had to be a part of it, it forced everyone to be part of this group and pay attention and give some input because they knew it would tie in later on. In the tutorials it was the same way. It forced us to interact with one another and use each other to help one another.

The focus group discussions and answers to the test revealed a strong sense of collaborative learning. Another student, commenting on the fact that officers in his corporate group all had different research questions to upload to the CKB, stated,

I also thought it was great that because each role was assigned different questions for the exercises, I learned 5 times the amount I would have in the same amount of time, more effectively. My group members would explain their findings instead of me having to research them myself.

Another goal of the study, beyond successful adherence and enactment of the model, was developing a curriculum which created a pathway for individuals to excel. When developing the business plan assignment, care was given by the professor to spread responsibility for its execution across offices held. However, as in any group task, there were areas of responsibility that were more complex and required deeper inquiry and hours spent to execute responsibilities for the development of the business plan.

The CFO and VP Marketing and Sales were identified by the professor as the two "officer" positions upon which the heaviest workload was placed. Since these positions were self-selected, an 
analysis of their grades was undertaken, using a scale of $0-3$ (corresponding to $\mathrm{B}+$ or below, A-, A, or $\mathrm{A}+$ ). The median score for V.P. Marketing and Sales was 1.58. The CFO scored 1.35. The two positions deemed less demanding by the practitioner, V.P. Legal and CEO scored 1.19 and 1.18 respectively. The outlier was the COO position, which received the second highest score of 1.44 . When asked to rate the most demanding to least demanding offices, focus group members agreed with the researcher's assessment, rating $\mathrm{CFO}$ and VP Marketing as the most demanding and $\mathrm{CEO}$ and $\mathrm{COO}$ as least demanding, VP Legal hovering in the middle. Verbosity is not necessarily an indicator of effort, engagement or quality in research, but a word count of each of the five workbooks in the CKB revealed that the CFOs wrote 81,095 words over the five exercises, the most of any officer group with the VP Marketing group writing the next highest amount (Table 5). The CEOs wrote $5 \%$ fewer words than the CFO group, ranking fourth, the VP Legal group writing the least, at almost $10 \%$ fewer words. Triangulation of this data with final grades, the focus group officer difficulty evaluation, the professor's assessment of that same metric, and self-selection as to role, identified a trend. A highly motivated student who is invested in his or her academic success and interested in the subject matter is inclined to accept more responsibility and more difficult tasks, especially when being assessed as a group, to ensure a high grade and to contribute to their career ambitions.

\section{Discussion}

The two iterations each demonstrated that an FCL curricular design could be modified for the delivery of a university-level course. The 1st iteration was shown to effectively adhere to FCL principles. About half of the lectures qualified as benchmark lessons, foundational topic introductions delivered by guest experts or the professor. Learning communities were fostered, but not the whole lecture course; rather, there were 12 discreet communities corresponding to the 12 tutorials.

In the 2nd iteration, the CKB became the nexus between lecture and tutorial, providing students with the opportunity for individual inquiry, research sharing with others and encouraging collaborative learning within groups. Many students described the $\mathrm{CKB}$ research activities as occasions in which they were "forced" to research, or "pushed" to explore topics. In general, the 2nd iteration succeeded in linking lectures, tutorials and individual inquiry so that a community of learners could develop. Students in both the reflective test and focus groups attested that the CKB was a means by which they researched deeply into their roles and responsibilities, learned from their peer's work, worked collaboratively through reciprocal teaching to learn about each other's roles, and gained expertise for future positions in the media industry. The curricular design, and the CKB in particular, also rewarded students willing to go above and beyond what was required for the course, and were rewarded with higher grades. As one student stated, "These CKB exercises have encouraged us to go out and learn more than what was taught during the lectures and to share what we learned with everyone else so that they too may benefit from this." The CKB served not only as a repository of individual inquiry, but a discussion point during lectures, where students were randomly chosen to explain their research, and in tutorials, where corporate groups reviewed individual research and shared it amongst themselves and the other groups within the tutorial.

Students, by way of individual inquiry and collaborative knowledge building, worked together to create a real-life artifact, the business plan. Students also demonstrated acquired knowledge in a curriculum that spanned a wide range of topics. Learning outcomes were achieved and overall the course was well received. But how well was a learning community created beyond the tutorials and what impact did this have on learning? The addition of the CKB and the ensuing discussions the student research generated in the lectures is a good start, but despite some evidence that a sense of community was established class-wide, it is impossible to state what effect that had on learning. Thus, it is important to reserve any claims about the effect of a learning community approach on learning - if only to spur future research in this area and further guide future iterations that reinforce this sense of community.

The researcher in his role of professor concluded that the more the subject matter and activities resembled real-life experiences, the more likely university students were to perceive the course, the activities, and the professor with credibility. Therefore, if a learning community approach installs real-life situations and artifacts into the curriculum, i.e., if students detect a direct link between the learning community activities and succeeding in the work place, the more likely the course will be accepted as having value. Unless students perceive practical, skill enhancing value in their research and the artifacts they create in a course, these activities will be relegated to an exercise that must be completed for a grade and nothing more. Unfortunately, as earlier stated, learning communities take time to develop [7], and time in this study is a commodity that is dictated by a 12 week term. The best one can hope for is to expose students to the concept and have them experience the early stages of a learning community developing. To expect more from this design would border upon hubris. Researchers in education have long lamented that their applied research is rarely adopted by 
boards or institutions. To foster communities of learners, which may take years to develop, would necessitate entire faculties or the office of Provost to make the learning community approach a mandated feature. Professors of a certain age with pedagogical techniques that have proved tried and true will likely be resistant to a template that requires a transformative new approach with not a plethora of research to guarantee results worth the effort. But newer faculty, younger, may be willing to adopt this framework if it can be demonstrably shown that this approach is better for students and for themselves as instructors in the 21 st century. If educators believe in the university experience as a vital factor in future success, then it is important for students to see their university education as providing them with the academic skills they will use throughout their lives. Active learning, where students participate in handson, real-life activities will connect for students their experience in school with later experiences after graduation and reinforce a positive attitude towards the institution where they learned these skills.

\section{Conclusion}

An FCL-focused curricular design can engage a large lecture university course, providing students with an inquiry learning environment, promoting active learning, collaboration, and a knowledge community ethos for the entire class. The relatively simple digital tool of a Google Doc became the connector between lecture, tutorial and individual inquiry. Repetition in the design, where a topic was initially the subject of individual inquiry, then became the content for classwide discussion in lectures, and finally, was referred to again within tutorial groups, reinforced a sense of learning community within tutorial groups, each tutorial section, and in the large lecture. Future iterations should consider more sophisticated digital resources for the CKB, as a Google Doc with 48 authors was at times awkward to manage and difficult for students to navigate. While this FCL model, modified for university courses, has the potential to be used as a template for other courses, the researchers recognize the challenge inherent in convincing professors to adopt an FCL curricular design, and the buy-in required by students to actively participate as a knowledge community.

\section{References}

[1] Brown, A. L., and Campione, J. C. (1996). Psychological theory and the design of innovative learning environments: On procedures, principles, and systems. In Schauble, L. and Glaser, R. (eds.) Innovations in learning: New environments for education, (pp. 289-325). Mahway, NJ: Erlbaum.
[2] Vygotsky, L. S. (1978). Mind in society: The development of higher psychological processes. M. Cole, V. John-Steiner, S. Scribner, and E. Souberman, (eds. and trans.). Cambridge, MA: Harvard University Press.

[3] Brown, A.L. and Campione, J.C. (1994). Guided discovery in a community of learners. In McGilly, K. (ed.) Classroom Lessons: Integrating Cognitive Theory and Classroom Practice, (2nd ed.) (pp. 229-270). Boulder, CO: Bradford Publishing.

[4] Slotta, J. D., and Najafi, H. (2013). Supporting collaborative knowledge construction with Web 2.0 technologies. In Emerging Technologies for the Classroom (pp. 93-112). New York: Springer.

[5] Slotta, J. D., and Peters, V. L. (2008). A blended model for knowledge communities: Embedding scaffolded inquiry. International Perspectives in the Learning Sciences: Crea8ing a learning world. Proceedings of the Eighth International Conference for the Learning Sciences - ICLS 2008 (pp. 343-350). International Society of the Learning Sciences, Inc.

[6] Sherin, M. G., Mendez, E. P., and Louis, D. A. (2004). A discipline apart: The challenges of "Fostering a Community of Learners" in a mathematics classroom. Journal of Curriculum Studies, 36(2), 207-232.

[7] Scardamalia, M. (2002). Collective cognitive responsibility for the advancement of knowledge. In Smith, B. (ed.) Liberal Education in a Knowledge Society (pp. 67-98). Chicago, IL: Open Court.

[8] Slotta, J. D., and Najafi, H. (2010). Knowledge Communities in the Classroom. In P. Peterson, E. Baker, and B. McGaw (eds.), International Encyclopedia of Education Vol. 8, (pp. 189-196). Oxford: Elsevier.

[9] Peters, V.L., and Slotta, J.D. (2010). Scaffolding knowledge communities in the classroom, New opportunities in the Web 2.0 era. In M.J. Jacobson and P. Reimann (Eds.), Designs for learning environments of the future: International perspectives from the learning sciences (pp. 205-232). New York, NY: Springer.

[10] Scardamalia, M., and Bereiter, C. (2010). A Brief History of Knowledge Building. Canadian Journal of Learning and Technology, 36(1), 1-16.

[11] Anderson, T., and Shattuck, J. (2012). Design- Based Research: A Decade of Progress in Education Research? Educational Researcher, 41(1), 16-25.

[12] Scardamalia, M., Bereiter, C., and Fillion, B. (1981). Writing for results: A sourcebook of consequential activities. Toronto: OISE Press. 